\title{
COMPARISON AND SUBHOMOGENEITY OF INTEGRAL MEANS
}

\author{
LÁSZLÓ LOSONCZI
}

Abstract. The differential and integral means were defined and studied by Elezović and Pečarić [3]. They gave sufficient conditions for the comparison of two integral (differential) means and applied this to obtain some other inequalities.

Our aim is to give necessary and sufficient conditions for the comparison of two integral means and in this way improve theorems 2,3 of [3]. We also deal with the subhomogeneity and homogeneity of integral means. As they are special Cauchy means we can use the method of the author [7] to prove our results.

Mathematics subject classification (2000): Primary 26A15.

Key words and phrases: integral mean, Cauchy mean value, inequalities.

\section{REFERENCES}

[1] J. ACZÉL, Lectures on functional equations and their applications, Academic Press, New York, 1966.

[2] G. T. CARGo, Comparable means and generalized convexity, J. of Math. Anal. and Appl. 13 1965, 387-392.

[3] N. ElEZOVIĆ AND J. PEČARIĆ, Differential and integral $f$-means and applications to digamma function, Math. Ineq. Appl., 3 2000, 189-196.

[4] G. H. Hardy, J. E. Littlewood And G. Pólya, Inequalities, Cambridge at the University Press, 1952.

[5] L. Losonczi, Subhomogene Mittelwerte, Acta Math. Acad. Sci. Hung. 22 (1971) 187-195.

[6] L. LosonczI, Inequalities for integral mean values, J. Math. Anal. Appl. 61 (1977), 586-606.

[7] L. LosonCZI, On the comparison of Cauchy mean values, J. of Inequal. and Appl. 7 2001, 1-14.

[8] A. W. Roberts and D. E. VarberG, Convex Functions, Acad. Press, New York and London, 1973.

[9] K. B. StOlarsky, Generalizations of the logarithmic mean, Math. Mag., 48 1975, 87-92.

[10] K. B. StOlarsky, The power and generalized logarithmic means, Amer. Math. Monthly, 87 1980, 545-548. 